\title{
A IMPLEMENTAÇÃO DE AÇÕES NEOLIBERAIS NAS UNIVERSIDADES
}

\section{PÚBLICAS $^{1}$}

\author{
Tânia Maria Granzotto ${ }^{2}$
}

\section{RESUMO}

Este artigo apresenta uma reflexão acerca da inserção das universidades públicas na lógica do capital e as consequentes mudanças no interior destas instituições em âmbito político, econômico e ideológico. Analisa os diversos fatores que configuram um universo acadêmico de mercado, com a introdução de novos conceitos e ideários, tais como: “insumos”, “clientes”, “produtividade”, “qualidade total” e tantos outros. Nesse contexto neoliberal, algumas consequências abordadas incluem: redução de verbas para pesquisa, terceirização do trabalho, ênfase na pesquisa tecnológica e produtivismo acadêmico.

PALAVRAS-CHAVE: Universidade, Neoliberalismo, Precarização do Trabalho, Terceirização.

\section{INTRODUÇÃO}

Compreender as transformações ocorridas no mundo do trabalho nas últimas duas décadas pressupõe salientar que elas desenvolveram-se não apenas no setor privado, mas também na esfera pública, constituindo-se num processo crescente e contínuo através dos sucessivos governos.

Neste artigo não temos a pretensão de aprofundarmos acerca das implicações das ações neoliberais inseridas nas universidades públicas, porém, pretendemos apresentar algumas reflexões feitas a partir de nossos estudos sobre o universo

\footnotetext{
${ }^{1}$ Este artigo é parte da tese de doutorado: "O Movimento Sindical na Academia: o caso das Universidades Estaduais Paulistas”, defendida em 2010 na Faculdade de Educação da UNICAMP.

${ }^{2}$ Assistente Social da Coordenadoria de Serviços Sociais - CSS/UNICAMP, mestre e doutora em Educação pela Faculdade de Educação da UNICAMP.
}

Revista Serviço Social \& Saúde. UNICAMP Campinas, v. X, n. 12, Dez. 2011 
acadêmico. Nesse sentido, nos propomos a sinalizar inúmeras situações em que se verifica a implantação destas ações no interior das universidades em questão, com suas respectivas consequências.

Uma importante questão a frisar é a crescente terceirização implementada nestas universidades e os novos métodos adotados de gestão e avaliação do trabalho.

\section{O NEOLIBERALISMO INSERIDO NA ACADEMIA}

A sutil implementação de ações neoliberais nas universidades públicas pode ser percebida de várias formas, tais como: tratar a Educação como mercadoria e não como um direito, terceirização dos serviços (contratos de trabalho realizados através das fundações privadas e de empresas terceirizadas), flexibilidade das relações de trabalho (tanto para a categoria de funcionários, como para a categoria dos docentes), corte de verbas, parcerias público-privadas, etc. Para entendermos esse fenômeno é necessário que nos reportemos à década de 1990, onde se acentuou o processo de implantação das ações neoliberais nas universidades públicas.

No que se refere às ações neoliberais no âmbito da Reforma do Estado, de acordo com Chaú (2003), a universidade pública sofreu mudanças nos últimos anos em virtude dessa reforma. Quando ocorreu a reforma houve uma redefinição dos setores do Estado e a educação deixou de ser concebida como serviço exclusivo do Estado e passou a ser considerada como um serviço que pode ser privatizado.

Com a reforma do Estado a universidade também mudou de instituição social para organização social, o que pressupõe que passa a ser regida pelo pensamento da gestão, do planejamento, do controle e êxito, da prestação de serviços. Ainda, segundo essa autora, a universidade passou a ser regida por contratos de gestão, avaliada pela produtividade e estruturada por programas de eficácia organizacional. Desta forma vem 
ocorrendo a exigência de titulação, o aumento de horas/aula, a redução autoritária dos prazos para mestrados e doutorados, a imposição de relatórios de atividades, avaliação pela quantidade de artigos publicados e eventos, tais como: congressos e simpósios.

O critério produtivista que vem permeando os modelos de avaliação institucional, referenciada pelo modelo da CAPES, traz, para a universidade, a lógica do mercado, ou seja, a produção científica perde o seu valor de uso e torna-se valor de troca, vide modelos de avaliação equivocados e mercadológicos [...] (GRADELLA JR., 2002, p. 34).

Sendo assim, constroem-se no âmbito educacional termos pertencentes ao discurso neoliberal, tais como: adequar o ensino às exigências do mercado, qualidade total, parcerias entre as universidades públicas e o setor empresarial, pesquisas voltadas para o mercado, sistema de avaliação e produtividade etc.

Os processos de privatização do conhecimento, ou seja, o conhecimento gerado no setor público com financiamento privado limitam o livre fluxo do conhecimento, bem como ocorre uma estimulação da preferência por temas de pesquisa "rentáveis", sendo que se avalia o trabalho acadêmico segundo critérios empresariais. Nesse universo, os efeitos sobre a autonomia universitária são geralmente limitados e condicionados pela lógica do mercado (NAIDORF, 2005).

Reduzida a uma organização, a universidade abandona a formação e a pesquisa para lançar-se na fragmentação competitiva. Mas por que ela o faz? Porque está privatizada e a maior parte de suas pesquisas é determinada pelas exigências de mercado, impostas pelos financiadores. Isso significa que a universidade pública produz um conhecimento destinado à apropriação privada (CHAUÍ, 2003, p. 8). 
Dessa forma, a ciência deixou de ter uma utilização prática, passando a configurar-se numa engrenagem do próprio capital. Isso explica as novas modalidades de financiamento para a pesquisa, a postura de submetê-la aos requisitos do capital e a mudança da universidade para organização ou entidade operacional.

Ao se tornarem forças produtivas, o conhecimento e a informação passaram a compor o próprio capital, que passa a depender disso para sua acumulação e reprodução (CHAUÍ, 2003, p. 8).

Vale mencionar que a atividade no setor de serviços produz trabalho imaterial e este não é suscetível a uma racionalização técnica quando comparado com o trabalho produtivo, ou seja, que gera bens de consumo. Portanto, a produtividade da atividade desenvolvida no setor de serviços não pode ser mensurada e, devido a isso, o fator produtividade não pode ser controlado (OFFE, 1989).

Avaliar a produtividade de um professor universitário é mais complicado que medir a produtividade de um cortador de cana. As tarefas são variadas - em geral classificadas nas categorias Ensino, Pesquisa, Extensão - sem deixar de incluir a categoria Administração Universitária (BURIAN JR., 2009, p.15).

Desde a década de 1990 estamos assistindo ao desmonte da universidade pública brasileira, com a inserção destas na lógica do capital. Devido à redução das verbas para as universidades, o que ocorre é a captação de recursos financeiros junto ao setor privado e ao mercado.

O fato extremamente grave é que a educação passou a ser considerada serviço, ao mesmo nível dos serviços prestados pelas empresas comerciais. E a OMC se dá o direito de negociar medidas para eliminar os obstáculos ao livre acesso ao mercado de serviços, entre eles, evidentemente, a educação (SALMERON, 2002, p. 4). 
Dessa forma, a educação deixa de ser considerada um processo e passa a ser mercantilizada, ou seja, considerada uma mercadoria, ou mesmo um serviço que pode ser comercializado como qualquer outro. As pesquisas passam a ser realizadas conforme as demandas do mercado.

$\mathrm{Na}$ “nova ordem econômica internacional” que desponta, a universidade é pressionada a se especializar no seu papel tradicional de agência formadora da elite intelectual burguesa, que passa a se constituir como setor profissionalizado (técnico) do sistema econômico-político (COELHO, 1996, p. 170).

O que vem predominando em âmbito mundial é um ideário tecnocráticomercantilista, o qual privilegia o investimento em pesquisas na área tecnológica em prejuízo das pesquisas na área de ciências humanas, as quais são relegadas para um segundo plano.

Nos tempos atuais, para lembrar as expressões dominantes, não é lucrativo nem rentável optar pelos caminhos da filosofia, da história ou das ciências sociais. Embora alguns, através das ciências humanas e da filosofia, possam alcançar postos de destaque e de projeção na vida social, estas nossas vocações teóricas não tem o prestígio e a rentabilidade de outras profissões e carreiras. Os interesses do mercado frequentemente divergem daqueles que privilegiam o desenvolvimento do espírito e do pensamento críticos (TOLEDO, 2002, p. 2).

Na ótica do governo e dos organismos internacionais, as universidades de pesquisa só deveriam ser mantidas em reduzido número, para atender aos interesses do mercado através da Lei de Inovação Tecnológica. Paralelo a isso funcionariam várias outras, preferencialmente do setor privado, voltadas apenas para o ensino e com o objetivo de formar quadros em tempo reduzido. Conforme Boito Jr: 
A redução dos gastos sociais acompanha espontaneamente a defesa da privatização dos serviços públicos e possui como justificativa própria a ideia de que esses serviços são apropriados, em grande parte, pelas camadas de renda média e alta em detrimento da camada mais pobre da população. Em suma, o mercado é o lugar da eficiência e da liberdade individual, enquanto o Estado é o lugar da ineficiência e do privilégio (BOITO JR, 2002, p. 63).

Conforme esse autor é importante considerarmos o caráter ideológico desse discurso. Em relação as universidades públicas também vem ocorrendo a adesão a esse ideário.

A universidade pública, que deveria prestar um serviço à sociedade no sentido de implementar um projeto social democrático, passou a promover a cultura do produtivismo, a qual privilegia a pesquisa em prejuízo às atividades de ensino e extensão. Dessa forma, ocorreu uma hierarquia nos campos do saber, ou seja, algumas áreas do saber teriam maior valor do que outras. O que está por detrás disso é a lógica do mercado, implementada através do financiamento diferenciado de pesquisa. A partir daí, a pesquisa só tem valor quando é publicada em revistas acadêmicas de alto nível, gerando uma corrida em busca da produtividade científica e num estado de não reflexão (ADUNICAMP, 2002).

A ética produtivista não acrescentou nada à função social da Universidade. A política do publish or perish conduziu a uma disputa acirrada entre grupos de pesquisa, canais de publicação e a um abandono cada vez maior da graduação (ADUNICAMP 2002, p. 24).

Dessa forma, os docentes ficam engendrados em seu cotidiano numa perspectiva individualista, cada vez se esforçando mais para atender as demandas do 
produtivismo acadêmico e não refletindo sobre a sua ética, ou sobre o seu futuro e da própria universidade.

Conforme Naidorf (2005), nos países latino-americanos o setor privado tem se inserido nas universidades públicas, constituindo-se numa base diversificada de financiamento e, assim, permitindo que as universidades públicas sobrevivam no atual contexto de restrição das verbas públicas. Embora essa tendência se impôs na América Latina desde meados da década de 1980, na década de 1990 ocorreu seu aprofundamento e aceleração. Com isso, surgiu uma nova cultura nas universidades públicas, que é o fortalecimento da vinculação das atividades acadêmicas com o setor produtivo.

A autora refere que na Argentina, a partir das transformações ocorridas nos últimos anos, a universidade vem sendo obrigada a competir por subsídios que em décadas anteriores eram fornecidos pelo Estado. Conforme nossa pesquisa também demonstrou, o mesmo vem ocorrendo no panorama universitário do setor público brasileiro.

Quando a Universidade começa a se gerenciar pela lógica privatista empresarial, começa a apertar seus vínculos com empresas privadas que induzem o que deve ser pesquisado ou produzido, cedendo a "pressões do mercado”, significa que a sua dimensão pública e universal está seriamente debilitada. A facilidade com que a autonomia (muito relativa) da Universidade foi comprimida com a criação da Secretaria Estadual de Ensino Superior mostra muito da regressividade privatista do nosso tempo (ROIO, 2008).

No Brasil, em 1997 o governo FHC lança um pacote de medidas que, entre outras, preconizam o corte de verbas na Saúde, na Educação, na Ciência e Tecnologia, sendo que o CNPQ e a CAPES tem 12,5\% de seus recursos cortados (ADUNESP, 
2007). Sendo assim, com as ações neoliberais adotadas pelo Estado, essas ações, consequentemente, acabam sendo implementadas também em outras instituições públicas pertencentes ao aparelho de Estado, no caso, as universidades públicas.

Tomemos como exemplo o projeto de expansão das Universidades Estaduais Paulistas, o qual está sendo executado sem dotação adequada de verbas, o que vem acarretando salas de aula abarrotadas, infraestrutura precária, falta de quadros funcionais, queda na qualidade do ensino, ausência de verbas para a pesquisa, implementação de novos cursos com um perfil distinto dos demais, cursos à distância, etc. Resta saber: quais intelectuais serão formados a partir dessas mudanças nas universidades?

No projeto de ensino à distância da UNIVESP, foram criadas cinco mil vagas na UNESP pra pedagogia, sem você discutir efetivamente o que significa cinco mil vagas à distância em pedagogia. Porque não na Medicina, porque não em outras áreas? E aí fala pro sindicato que nós éramos contra porque somos ultrapassados. Mas foi aprovado cinco mil vagas na UNESP e na USP setecentas vagas; olha a diferença! ${ }^{3}$

De acordo com Roio (2008), em 2003 foi definido pelas três universidades um programa de expansão de cursos e vagas, sendo que na UNESP isso se tornou mais crítico, pois se resolveu realizar uma extensa ampliação sem planejamento adequado e sem a contrapartida de recursos. Neste caso, interesses de ordem privada estariam se sobrepondo aos interesses públicos. A democracia e autonomia da instituição foram deixadas em segundo plano, em benefício de acordos políticos com setores locais e interesses individuais.

\footnotetext{
${ }^{3}$ Entrevista realizada com ex-dirigente da ADUNESP em 20/03/2009. Revista Serviço Social \& Saúde. UNICAMP Campinas, v. X, n. 12, Dez 2011
} 
Esse processo de transformação da universidade pública no Brasil ocorre em virtude da implantação do modelo neoliberal, sendo que o que está posto para a universidade pública é que seja uma instituição econômica rentável, que presta serviços e formadora de mão-de-obra especializada e, conforme já mencionado, de acordo com as demandas do mercado.

É um projeto mundial. Um projeto do Capital. O Banco Mundial é um financiador desse projeto. E o projeto é transformar o universitário em um operador do sistema. No primeiro mundo, nos países ricos, ele é um operador de primeira grandeza, ocupa os maiores postos, e no mundo subdesenvolvido ele é um operador auxiliar. Vai fazer um trabalho, digamos, secundário, rotineiro, já estabelecido, não vai estar na vanguarda da descoberta tecnológica, na vanguarda do pensamento filosófico, na vanguarda do pensamento econômico. Vai estar atrás, aplicando os instrumentos que já foram desenvolvidos (SAMPAIO, 2009, p. 4).

Levando-se em conta que as universidades em questão são públicas, o financiamento das mesmas deve ser através de verbas públicas, ou seja, do Estado, para serem aplicados em questões de ordem pública e não poderiam ser utilizados em benefício da esfera privada, ou seja, do mercado. Porém, o que vem ocorrendo é que grande parte da pesquisa gerada nas universidades públicas, está sendo financiada por agências externas.

Conforme argumentação de outro autor, a universidade pública vem sofrendo, nos últimos anos, ameaças veladas ou mesmo abertamente, as quais compreendem: o ensino pago, a substituição apenas parcial de docentes e funcionários, o corte de verbas para a pesquisa, os ataques à FAPESP e à autonomia financeira parcial das Universidades Estaduais Paulistas (CANO, 1997). O programa neoliberal pretende 
implementar a privatização do maior número possível de estatais ou instituições públicas, sendo que a universidade surge como uma referência para que seja alcançada a racionalização dos recursos.

A insuficiência dos recursos destinados às universidades, aliada ao desenvolvimento e enraizamento do pensamento neoliberal de necessidade de esvaziamento das funções do Estado, criaram contradições importantes no interior da comunidade universitária. A lógica da eficiência, do pragmatismo, da universidade de resultados, do enxugamento da máquina e outras manifestações “moralistas” refletem a incorporação do discurso oficial e até mesmo sua defesa. A incorporação desse discurso tem levado a uma resistência da comunidade na luta por mais verba e por melhores condições de trabalho e salários. Ao mesmo tempo, criou as condições para um aprofundamento do processo de privatização da universidade no seu sentido mais amplo, via convênios e repasse de tecnologias para o setor privado e indústrias de ponta no relacionamento universidade/empresa (FREITAS, 1991).

A Reforma Universitária configura-se na implementação dos processos de privatização com ações produtivistas, aprofundamento da precarização das relações de trabalho, promoção de gratificações ao invés de política salarial, extinção da carreira e da isonomia, diversificação das fontes de financiamento, diferenciação das instituições, expansão das universidades, prioridade do ensino à distância, autonomia financeira das instituições públicas através da captação de recursos e a regulamentação da relação entre universidades e fundações privadas.

Assim sendo, as mudanças que vem permeando a educação e transferindo-a do contexto do público para o privado, podem ser listadas como: 1) redução do financiamento público da educação de ensino superior; 2) grande 
expansão e incentivo da educação do setor privado com a adoção de processos de mercantilização dos serviços; 3) processo crescente de privatização interna das universidades públicas com vendas de serviços, consultorias, fundações de apoio. 4) novas empresas que promovem o comércio de serviços educacionais, consórcios de instituições públicas e privadas, escolas autogestionadas e outras. 5) novos mecanismos de avaliação, coordenação, controle, administração gerencial, competição; 6) indústria de dispositivos pedagógicos extra escola, mercado de produtos escolares e serviços especializados (CAMARGO et al, 2003).

Constitui-se um exemplo de ações neoliberais na universidade a criação de programas de apoio à pesquisa que promovem o relacionamento entre empresas privadas e universidades públicas.

Como já apontado, um grande problema hoje em dia no setor público e também nas universidades públicas, acarretado pelo neoliberalismo, é o contínuo processo de não reposição dos funcionários e docentes. Vejamos como exemplo o caso das universidades públicas, onde se observa a insuficiência de docentes e funcionários. Os reitores quando são questionados, justificam que o processo de terceirização dos serviços e a flexibilização dos contratos de trabalho nas universidades públicas, traduzse num modo de economizar recursos em algumas áreas, a fim de inserir recursos nas atividades fins. Porém, esta prática se configura numa privatização "pelas bordas”, ou seja, são recursos públicos desviados para o mercado ocasionando a exploração dos trabalhadores e a crescente precarização das relações de trabalho.

Outra questão a ser analisada é que a terceirização em alguns setores, poderá tornar-se o carro chefe para a total privatização das universidades públicas. A terceirização é um recurso utilizado nas universidades para suprir a falta de funcionários, a qual se apresenta atualmente em todas as áreas, sendo que essas 
contratações são viabilizadas através das fundações ditas “de apoio” e contratos com empresas externas. Conforme salientou Gentilli:

A modalidade mais visível (e denunciada) de privatização educacional vincula-se à delegação da responsabilidade do financiamento estatal para entidades privadas. O Estado vai reduzindo sua participação como agente central na alocação dos recursos destinados ao financiamento dos serviços educacionais, transferindo essa responsabilidade aos próprios indivíduos, às famílias ou às empresas (GENTILLI, 1998, p. 77).

Conforme Leher e Lopes (2008), os serviços de infraestrutura das universidades públicas já estão, em grande parte terceirizados, tais como: setor de limpeza, segurança, alimentação e até mesmo a docência na graduação vem sendo realizada por docentes substitutos, colaboradores e doutorandos.

A terceirização tem significado nas últimas décadas a ampliação do estatuto salarial precário no Brasil, com destaque para o corpo de trabalhadores públicos da USP. Mais do que nunca se explicita a condição de "proletários do Estado". Ora, embora os trabalhadores terceirizados da USP não sejam, no sentido estrito do contrato de trabalho, funcionários públicos da Universidade de São Paulo, eles são membros do "trabalhador coletivo público" que contribui para o funcionamento da mais importante instituição de ensino e pesquisa do país. Portanto, uma parte do complexo vivo de trabalho da USP vive sob condições contratuais precárias - e talvez, sob grave situação trabalhista (ALVES, 2010, p. 17).

Nessa mesma linha de pensamento, convém assinalar que um outro recurso que está sendo amplamente utilizado nas universidades públicas é a contratação de estagiários e bolsistas em substituição à contratação de funcionários e docentes, com o objetivo de pagar salários bem mais baixos e ter a isenção de encargos previdenciários, Revista Serviço Social \& Saúde. UNICAMP Campinas, v. X, n. 12, Dez 2011 
recolhimento de FGTS, etc. Desta forma, no mesmo serviço público há trabalhadores estáveis, com aposentadoria integral, com vários benefícios, e trabalhadores precarizados, sem direito a esses benefícios.

Há alguns anos a ADUNESP denunciou no Ministério Público a prática da contratação de professores conferencistas, os quais permaneciam vinculados à UNESP apenas por $89^{4}$ dias, sendo que, a partir desta denúncia posteriormente essa prática deixou de ser implementada. Porém, os contratos por tempo determinado ainda permanecem, como é o caso dos docentes que são contratados por um ou dois semestres.

A falta de docentes e os contratos precários se disseminou. Hoje nós temos na UNESP 500 docentes, ou um pouquinho mais provavelmente, substitutos contratados por um semestre. Isso em termos de qualidade de ensino é muito complicado, porque não tem nenhum comprometimento com o programa que está sendo desenvolvido. Ele vem, cai de paraquedas para dar uma disciplina dentro de um contexto já montado. O professor não cria raízes porque ele vai sair e porque pode renovar contrato só por um semestre. Isso vem acontecendo desde 2003, 2004, quando houve o processo de expansão e a segunda Reforma da Previdência em 2003, em que muitos docentes se aposentaram e não teve reposição ${ }^{5}$.

Outro fato é que na última década observa-se um visível redirecionamento das pesquisas para o mercado com um questionamento do caráter público das universidades.

As contrarreformas originadas nos acordos de Bolonha, nas fórmulas bancomundialistas e nas proposições dos Tratados de

\footnotetext{
${ }^{4}$ Essa prática de contratar por 89 dias era realizada porque a partir de 90 dias cria-se o vínculo empregatício.

${ }^{5}$ Entrevista realizada com ex-dirigente da ADUNESP em 20/03/2009.

Revista Serviço Social \& Saúde. UNICAMP Campinas, v. X, n. 12, Dez. 2011
} 
Livre Comércio (e em nível nacional, nas Parcerias PúblicoPrivadas - PPP) tornam a gestão nas universidades cada vez mais parecidas com a de uma empresa, esvaecendo o seu caráter de instituição da sociedade voltada para a formação humana e para a produção do conhecimento engajado na solução de problemas nacionais. A docência e a carreira acadêmica passam a ser balizadas por uma outra lógica. Como os professores são os principais agentes construtores da universidade, é possível supor que muitos docentes operam essas transformações e são por elas afetados (LEHER, LOPES, 2008, p. 20).

De acordo com Andrade (professor da UNESP) a política de incentivo e exigência do produtivismo acadêmico:

[...] incentiva na universidade pública os fazedores de pesquisas irrelevantes, de papers e artigos que só servem para ranquear e que pouco contribui para o desenvolvimento autossustentável da nação, da nossa ciência e tecnologia e da própria universidade (ADUNESP, 2007, p. 5 e 6).

Outra questão é o fato de existirem as fundações ${ }^{6}$ privadas de apoio dentro das universidades públicas, oferecendo cursos pagos e utilizando o nome das universidades públicas ${ }^{7}$, contratando funcionários com salários mais baixos e firmando contratos com o poder público sem licitação. O propósito destas fundações é diminuir a responsabilidade do Estado no financiamento das universidades públicas, oferecer serviços para o mercado e fomentar o ideário do privado dentro das instituições públicas.

As fundações não mais são do que entes privados intermediando a relação financeira entre órgãos públicos. Além da

\footnotetext{
${ }^{6}$ Há 111 fundações credenciadas na SESU do MEC, sendo a maioria vinculada c/ universidades federais e CEFETs (ANDES, 2008).

${ }^{7}$ Por exemplo, o nome USP, UNICAMP e UNESP possuem um alto poder de atração e status. Revista Serviço Social \& Saúde. UNICAMP Campinas, v. X, n. 12, Dez 2011
} 
insustentabilidade jurídica dessa relação e do desvirtuamento acadêmico, se utilizam da estrutura das universidades públicas para fechar negócios privados sem precisar passar por processos de licitação (ANDES-SN, 2008, p. 2).

O fato dos recursos públicos serem insuficientes na composição das receitas das Universidades faz com que alguns setores dessas instituições necessitem criar estratégias de captação de recursos junto a empresas, bem como oferecerem serviços ao mercado. Dessa forma, são criadas fundações de direito privado, as quais fornecem serviços ao mercado, tais como: consultorias, assessorias, cursos e todos estes serviços são cobrados. Isso vem acarretando a valorização de alguns institutos ou áreas da Academia, nem sempre devido à qualidade da sua produção acadêmica e sim como resultado da demanda externa dos seus serviços, sendo que, em contrapartida, as áreas de Ciências Humanas são deixadas à margem. Todo esse processo se configura numa privatização interna das universidades públicas, além do que ocorre um desrespeito com a questão da autonomia científica.

As fundações "de apoio" gozam de benefícios em relação às empresas privadas, como isenções fiscais, e uma parte substancial dos seus contratos é firmada com o poder público, sem licitação, para o que se valem, ainda que irregularmente, de dispositivos existentes na Lei de Licitações. O recurso da dispensa de licitação é fartamente usado, inclusive para contratação de serviços administrativos ou técnicos de rotina, que poderiam ser oferecidos por empresas através de licitação, ou executados pelos próprios funcionários da instituição pública contratante (CHRISPINIANO, 2006, p. 28).

Conforme Sader (2008), os que defendem a existência dessas fundações afirmam que as universidades públicas, sem elas, teriam padecido devido às grandes restrições de orçamento. Eles argumentam também que essas fundações são mais ágeis Revista Serviço Social \& Saúde. UNICAMP Campinas, v. X, n. 12, Dez. 2011 
na tarefa de estabelecerem contratos, se compararmos à burocracia presente nas universidades. O recurso orçamentário que essas fundações captam para as universidades não é significativo: “ no caso da USP, os recursos captados por suas mais de trinta fundações não ultrapassam $4 \%$ de seu orçamento [...] são fundações que se apoiam na universidade pública com fins particulares” (SADER, 2008). Esse nicho de mercado presente nas universidades públicas descaracterizam essas instituições enquanto setor público e minam seu compromisso social de prestar serviços gratuitos à sociedade.

De acordo com Teixeira (2006), as Universidades Estaduais Paulistas concentram $53^{8}$ fundações privadas “de apoio”, sendo quatro na Unicamp, 17 na Unesp e 32 fundações na USP, faturando dezenas de milhões de reais por ano. A existência das fundações privadas dentro das universidades públicas proporciona um processo contínuo de privatização do ensino público, pois ocorre o distanciamento do interesse pelo social em benefício do atendimento das demandas do mercado. Por essas e outras razões, atualmente as fundações estão sendo muito criticadas e questionadas, pois elas consomem horas de trabalho de docentes e funcionários, além de usufruírem de espaço físico e equipamentos das universidades, não havendo geralmente o retorno desses custos. Conforme Gradella Jr. (2002, p. 93),

A extensão e a prestação de serviços vêm representando, na universidade pública, com incentivo institucional através das fundações, uma forma de captação de recursos e complementação salarial do docente, como uma resposta às

\footnotetext{
${ }^{8}$ Das 53 fundações citadas, temos conhecimento das seguintes: na UNICAMP: FUNCAMP, FECAMP e FASA; na UNESP: VUNESP, EDUNESP, FUNDUNESP, FUNDIBIO, FUNVET, FAMESP, FEPAF, FAEPO, FUNDECIF, FACTE, FUNEP, FDCT, FUNDACTE, FEPISA, FUNDEPE, FUNDEB e FAPERP (MIRANDA, 2007); na USP: FUNDECTO, FCAV, FIA, FIPE, FIPECAFI, FUSP, FFM, FUNDESPA, FAFE, FDTE, ARCADAS, FUPAM, FEALQ, FCTH, FIPAI, FUVEST, ZERBINI, FAEPA, FUNDHERP, FUNCRAF, FUNDACE, FIPFARMA, FAFQ, FUNORP, FUNBEO, FUMVET, FIERP, VANZOLINI.
} 
reivindicações salariais e às críticas das condições de trabalho que são feitas aos gestores nesses últimos anos.

Assim sendo, ao ser liberada a prestação de serviços pagos por parte da universidade configura-se uma privatização interna desta através da implementação dos cursos pagos, gestão irregular de verbas públicas e outras implementações.

Conforme Brinatti e Helene (2008), as fundações privadas tem causado grandes prejuízos à universidade pública, pois ocorreu uma apropriação do espaço público pelo setor privado, em detrimento dos interesses da sociedade. Essas fundações denominadas "de apoio", na verdade se apóiam nas universidades, pois usam o nome e prestígio dessas instituições, seu espaço físico, seus docentes, estudantes e técnicos especializados.

Ainda, de acordo com os referidos autores, no passado elas construíram uma imagem pública positiva, devido ao discurso de permitirem agilidade e eficiência que o setor público não tem em virtude da burocracia estatal. Esses autores reconhecem as dificuldades burocráticas que estão presentes no interior das universidades públicas, mas esclarecem que é preciso simplificar a burocracia ao invés de promover a criação dessas fundações privadas que instituem interesses privados, os quais entram em conflito com os interesses públicos e coletivos.

A proposta de criação das fundações de apoio às instituições estatais de ensino superior (IES) não surge com o objetivo de oferecer agilidade a uma máquina emperrada, mas sim de diminuir a responsabilidade dos governos no financiamento integral das IES e fortalecer os elementos privatistas em seu interior, sobretudo aqueles capazes de oferecer serviços mercantilizáveis, em detrimento dos serviços socialmente necessários mas sem mercado comprador (DAVIES, 2006, p. 37). 
Segundo dados do Ministério Público, nas fundações privadas ocorrem as seguintes irregularidades: contratos ou convênios não relacionados com a universidade, cobrança de taxas e cursos, desrespeito à Lei de Licitações, ausência de prestação de contas e de orçamentos detalhados, intermediação irregular em atividades que deveriam ser realizadas pelas universidades e subcontratação (ANDES-SN, 2008).

Antunes (2001) em seu estudo denomina os trabalhadores terceirizados e subcontratados como um novo proletariado, o qual vem se expandindo em diversas partes do mundo e também atingindo os trabalhadores com especialização. Dessa forma, o mundo do trabalho ficou fragmentado, heterogeneizado, complexificado e precarizado.

Neste sentido, desregulamentação, flexibilização, terceirização, downsizing, “empresa enxuta”, bem como todo esse receituário que se esparrama pelo “mundo empresarial”, são expressões de uma lógica societal onde se tem a prevalência do capital sobre a força humana de trabalho, que é considerada somente na exata medida em que é imprescindível para a reprodução deste mesmo capital. Isso porque o capital pode diminuir o trabalho vivo, mas não eliminá-lo. Pode intensificar sua utilização, pode precarizálo e mesmo desempregar parcelas imensas, mas não pode extingui-lo (ANTUNES, 2001, p. 44).

Todos esses conceitos se encaixam perfeitamente no setor público e, especificamente também nas universidades públicas, onde atualmente os chefes são denominados como “gerentes”, há uma política de não abertura de concursos, ou mesmo a prática de contratações nas universidades no regime CLT e observa-se um "enxugamento" dos quadros semelhante ao que ocorre no setor privado. Nestas Universidades o processo de redução de concursos públicos correspondeu a um 
crescimento da subcontratação, da terceirização, dos contratos por tempo determinado e outras modalidades de precarização do trabalho.

A outra questão é a forma como, em determinado momento, as agências de fomento passaram a interferir naquilo que é um segmento importante da atividade acadêmica, que é a pesquisa. Estas agências passaram a ditar políticas de incentivo à pesquisa e de incentivo aos professores que trabalham com pesquisa de modo centralizado e independente da gestão das universidades. Esses fatores se relacionam porque, embora se tenha legalmente o pressuposto da autonomia da universidade, ou seja, a universidade deveria ter a autonomia de gestão, acadêmica, científica e administrativa, isso na prática não ocorre.

Uma radical mudança no modo de trabalhar nas universidades públicas a partir da qual a questão do financiamento das pesquisas passa a ser um elemento independente do trabalho docente e muitas vezes da própria instituição (BOSI, 2009, p. 29).

Neste contexto, cada vez mais e por vários fatores, fundamentalmente ligados a políticas econômicas do governo, incentiva-se nas universidades do país todo e nas Universidades Estaduais Paulistas também, uma fragmentação do trabalho acadêmico e o individualismo das pessoas, as quais deixam de ter a perspectiva de fazer o trabalho acadêmico coletivamente num espírito de cooperação e de equipe. Sendo assim, os docentes passam a fazer o trabalho acadêmico individualmente numa postura de concorrência entre si e entre diferentes grupos de pesquisadores.

Se você não faz parte do grupo dos seletos e privilegiados, esquece. Porque eles vão controlar as revistas indexadas, eles vão controlar os critérios de seleção dos artigos, eles mesmos vão avaliar os artigos que interessam, ou não interessam de ser publicados nas revistas internacionais, eles constituem uma 
espécie de máfia, a verdade é isso, uma máfia que na verdade condiciona o teu futuro e a tua vida profissional ${ }^{9}$.

Existe um novo núcleo nas relações sociais e profissionais dentro das universidades que vai se colocando cada vez mais forte, gerando uma contradição, pois à medida que isso vai tomando amplitude, transparece uma política que se traduz numa ofensiva contra a universidade pública muito forte.

Tudo isso acarreta algo que é pernicioso em si, nas relações sociais em geral, mas é pernicioso, em particular, no trabalho acadêmico que é o individualismo exacerbado. Por sua vez, esse individualismo que se instala, primeiro nas relações de trabalho e profissionais na instituição, acaba se refletindo na dificuldade também de organizar os docentes para questões mais abrangentes de atuação política na sociedade e da discussão do papel que a educação e que a universidade deve ter na sociedade.

Outra questão é que nas universidades públicas vem ocorrendo uma prática de destinação de verbas diretamente para os pesquisadores ou grupos de pesquisa, configurando na criação de "feudos” de pesquisa dentro das universidades. Isso nada mais é do que a implantação do projeto neoliberal do governo, que é transformar o docente em microempresário, ou seja, combinar o conhecimento científico com as demandas do setor privado. A esse respeito, Mills comparou o docente a um empresário:

É consultor de grandes companhias imobiliárias, de comissões de arbitragem entre patrões e empregados, montou seu escritório de pesquisas e vende seus serviços e o prestígio de tradicional imparcialidade da universidade a que pertence (MILLS, 1979, p. 152).

\footnotetext{
${ }^{9}$ Entrevista realizada com ex-dirigente da ADUNESP em 17/04/2009. 
De acordo com Bosi (2009), existem algumas áreas do conhecimento científico que são mais valorizadas pelo mercado do que outras, por exemplo: um médico ou agrônomo com ideias mercantilizáveis valeriam um alto preço, enquanto que os filósofos valeriam pouco.

Mas o fato é que a possibilidade de se "viabilizar" financeiramente tem tornado a docência universitária um lugar propício para a realização de negócios com o capital privado e, por seu turno, um lugar cada vez mais determinado pela lógica da competição (BOSI, 2009, p. 27).

A privatização das universidades públicas tornou-se visível, principalmente, através da cobrança de mensalidade em cursos de pós-graduação lato sensu, contrariando o que estabelece o artigo 206 da Constituição Federal de 1988, o qual determina que o ensino deve ser gratuito em instituições oficiais e, devido a isso, existem atualmente vários processos na justiça contra a cobrança e ressarcimento dos cursos pagos no interior destas Universidades.

Os cursos pagos se tornaram uma “indústria caça-níqueis” altamente lucrativa que atrai clientes por meio da divulgação de propagandas em TV, jornais, rádio e internet. Essa mercantilização do conhecimento compromete a liberdade acadêmica ao direcionar a formatação de cursos, currículos e pesquisa para atender aos interesses do mercado em detrimento das demandas sociais (ANDES-SN, 2008, p. 7).

Apesar das fundações afirmarem não ter como objetivo a obtenção de lucro, elas acabam atuando como empresas que buscam negócios rentáveis. Em algumas Unidades da USP, existe uma indústria de cursos pagos contrariando a Constituição Federal, a qual determina que sejam gratuitos os cursos ministrados na rede oficial de ensino (MINTO, CORREIA, POMAR, 2008). 
Diante de todo o avanço das ações neoliberais nas universidades públicas e no ensino público superior, talvez não seja mais possível reverter o quadro de destruição do público que se instalou no sistema universitário, bem como o avanço do processo de privatização e a disseminação de mecanismos de controle, avaliação e de decisão segundo os moldes privatistas. Conforme Lodi (1991):

É preciso que o sindicato recoloque a questão da luta salarial no contexto da luta pelo controle do processo do trabalho e da gestão da Universidade. No plano das relações com a sociedade é preciso lutar pela participação da Universidade num projeto de desenvolvimento econômico, científico, cultural e tecnológico que contemple a questão da democracia, da cidadania e dos direitos sociais.

Conforme apontou Chauí (2003), para conceber-se a universidade sob uma nova ótica é necessário exigir, em primeiro lugar, que o Estado não considere a educação através do fator do gasto público, mas sim como um financiamento social e político, o qual somente será viabilizado através da concepção de que a educação é um direito e não um privilégio ou serviço.

Ainda, de acordo com Oliveira (2009), estamos vivenciando um processo de regressão na sociedade, o qual está situado no campo dos direitos humanos e trabalhistas, sendo que o papel da universidade seria barrar esse processo de regressão com um instrumento fundamentado, primeiramente, nos direitos dos trabalhadores. Em um país profundamente desigual, a universidade teria como obrigação lutar para que o processo de regressão seja detido, promovendo assim, o avanço da sociedade.

A privatização nos moldes verificados no longo período do governo anterior só pôde se impor objetivamente a partir de uma política deliberada para desacreditar o padrão público, implementada inclusive por parte de um conjunto de docentes 
do próprio sistema público estatal, interessados em estabelecer plenamente a lógica privatista neste sistema, propícia à apropriação privada de seus produtos e de sua produção (MAAR, 2004, p. 28).

As universidades enquanto organismos sociais críticos, de reflexão e de construção de paradigmas, deveriam colocar em prática um projeto crítico, que tenha como objetivo a emancipação e o desenvolvimento da sociedade em substituição ao projeto que está sendo implantado, o qual é fundamentado na perspectiva do capital. Para tanto, o modo atual de administração das Universidades deveria ser substituído por um sistema de núcleos democráticos de fato, e não por reitores que assumem o protagonismo de “patrões” configurando um ambiente universitário autoritário e não democrático, até porque as Universidades aglutinam e promovem (ou deveriam promover) ideários críticos ao capitalismo instituído.

\begin{abstract}
This article presents thoughts on the insertion of public universities in the logic of capital and the resulting changes on the political, economical and ideological spheres. It analyzes the factors that configure an academic market universe, with the introduction of concepts such as: “input”, “customers”, “productivity”, “total quality” and many others. In this neoliberal context, some discussed consequences include: include: reduction of research funds, outsourcing of labor, emphasis on technological research and academic productivism.
\end{abstract}

KEYWORDS: University, Neoliberalism, Precarization of Labor, Outsourcing. 


\section{REFERÊNCIAS BIBLIOGRÁFICAS}

ADUNESP. Adunesp 30 anos de lutas! Revista ADUNESP, Agosto/2007.

ADUNICAMP. Adunicamp: 25 anos. Autonomia, democracia, participação. Adunicamp, 2002.

ALVES, G. Terceirização e precarização do trabalho na USP. Revista ADUSP, $n^{0}$ 46, Jan. 2010.

ANDES-SN. Fundações privadas e universidades públicas: uma relação incompatível. Brasília-DF. CADERNOS ANDES-SN, março/2008 e abril/2008.

ANTUNES, L. R. Reestruturação produtiva e sistema bancário: movimento sindical bancário brasileiro nos anos 90. Tese de doutorado/IE/UNICAMP, 2001.

BOITO JR, A. Neoliberalismo e corporativismo de Estado no Brasil In: ARAÚJO, A. M. C. Do corporativismo ao neoliberalismo. Estado e trabalhadores no Brasil e na Inglaterra. São Paulo: Boitempo, 2002.

BOSI, A. P. Avaliação como forma atualizada de dominação e intensificação do trabalho In: Produtividade e avaliação docente. Para onde vai a Universidade? Revista Movimento em Debate. ADUNICAMP, Ano 2, nº 3, maio 2009.

BRINATTI, M., HELENE, A. Universidades públicas e fundações privadas. Pouco ou nada daquele discurso de substituir o Estado, com vantagens, era verdade. Jornal Valor Econômico, 06/03/2008, p. A-18.

BURIAN JR, Y. Produtividade e avaliação. Quantidade ou qualidade? Qual a melhor maneira de se avaliar o que é produzido pelos docentes? In: Produtividade e avaliação docente. Para onde vai a Universidade? Revista Movimento em Debate. ADUNICAMP, Ano 2, nº 3, maio 2009. 
CAMARGO, E. A S. P.; PINO, I. R.; PACHECO, J.; PIOZZI, P.; GOERGEN, P.; OLIVEIRA, R. P. e SGUISSARD, V. Educação: de direito de cidadania a mercadoria. Revista Educação e Sociedade, vol. 24, set. 2003.

CANO, W. O silêncio da universidade. Jornal O Estado de São Paulo, 12/02/1997.

CHAUÍ, M. A. universidade pública sob nova perspectiva. Revista Brasileira de Educação, n. 24, RJ, Sept/Dec 2003.

CHRISPINIANO, J. Silêncio da reitoria protege atividade febril das fundações privadas na UNB. Revista do ANDES-SN, maio 2006.

COELHO, P. Sindicalismo na Universidade: um estudo do movimento docente. Santa Maria: SEDUFSM, 1996.

DAVIES, N. FEC tem servido a interesses pessoais e seu apoio à UFF está longe de acontecer. Revista ANDES-SN Especial, maio 2006.

FREITAS, H. C. L. A autonomia das universidades públicas paulistas. Revista Universidade e Sociedade. ANDES-SN, Brasília-DF, n. 2, p.36-38, nov. 1991.

GENTILLI, P. A falsificação do consenso. Ed. Vozes, 1998.

GRADELLA JR. A. Sofrimento psíquico e trabalho intelectual do docente universitário. Tese de doutorado, Faculdade de Filosofia e Ciências de Marília UNESP, 2002.

LEHER, R., LOPES, A. Trabalho docente, carreira e autonomia universitária e mercantilização da educação. VII Seminário Redestrado - Nuevas Regulaciones em América Latina. Buenos Aires, 3, 4 Y 5 de Julio de 2008.

LODI, L. H. A resistência dos docentes ao desmonte da Universidade pública e gratuita. Revista Universidade e Sociedade. ANDES-SN, n² 2, nov. 1991.

MAAR, W. L. O “espírito público” e a reforma universitária. Revista ADUSP, abril 2004. 
MILLS, C. W. A Nova Classe Média. RJ: Zahar Editores, 1979.

MINTO, C. A. CORREIA, C. T. e POMAR, P. E. R. Crise da UNB, Fundações 'de apoio’ e o MEC. In: Jornal Folha de São Paulo, cad. A, 18/04/2008.

NAIDORF, J. La privatización Del conocimiento público en universidades públicas. In: GENTILI, P. , LEVY, B. ( Orgs.) Espacio público y privatización del conocimiento: estudios sobre políticas universitarias en América Latina. Buenos Aires: CLACSO, 2005.

OLIVEIRA, F. Entrevista concedida ao Jornal da ADUNICAMP, Ano 2, $\mathrm{n}^{\mathrm{o}}$ 11, agosto/2009.

OFFE, C. Capitalismo desorganizado, transformações contemporâneas do trabalho e da política. São Paulo: Ed. Brasiliense, 1989.

ROIO, M. D. A universidade pública e o vírus do privatismo. Revista Espaço Acadêmico. Ago./2008.

SADER, E. A universidade pública deve abrigar fundações de direito privado? Disponível em: http//www.aduff.org.br/manchetes/20040714_emirsader.html-21k, acesso em 18/02/2008.

SALMERON, R. A . Escola privada e universidade pública In: LOUREIRO, I. E DELMASSO, M. C.(Orgs) Tempos de greve na universidade pública. Marília, UNESP, SP: Cultura Acadêmica, 2002.

SAMPAIO, P. A Entrevista concedida ao Jornal da ADUNICAMP, Ano 2, $\mathrm{n}^{\circ}$ 11, agosto/2009.

TEIXEIRA, A. Resistência à privatização das IES públicas segue forte em São Paulo In: Revista ANDES-SN, maio 2006.

TOLEDO, C. N. Universidade, intelectuais e pensamento crítico. Primeira Versão, $\mathrm{n}^{\circ}$ 104, IFCH/UNICAMP, abr./2002. 